\title{
Site Management and Use of Social Media by Tourism Businesses: The Case of Quebec
}

\section{Romain Roult ${ }^{1}$ / Marilyne Gaudette ${ }^{1}$ / Denis Auger ${ }^{2}$ / Jean-Marc Adjizian ${ }^{3}$}

e-mail: romain.roult@uqtr.ca, gaudette.marilyne@courrier.uqam.ca, denis.auger@uqtr.ca, jm.adjizian@gmail.com ${ }^{1}$ School of Management Sciences, University of Quebec, Montreal, Canada

2 University of Quebec, Trois-Rivières, Canada

${ }^{3}$ School of Human Kinetics, University of Ottawa, Ottawa, Canada

Roult, R., Gaudette, M., Auger, D., \& Adjizian, J-M. (2016). Internet Site Management and Use of Social Media by Tourism Businesses: The Case of Quebec. Czech Journal of Tourism, 5(1), 21-34. DOI: 10.1515/cjot-2016-0002

\begin{abstract}
Information and communications technology (ICT) has taken centre stage in recent decades in the world of tourism. Publicity and reservation strategies, in particular, are now developed through ICT. The rise of virtual, tourist communities has messed up ways to assess tourism products. This complete renewal of ways to interact with the customer requires tourism businesses to adapt to these new communication patterns. It is with regard to this issue that this study is based. A survey of 2393 Quebec tourism enterprises made it was possible to identify websites and use patterns of these organizations and social media. The results show that most companies are aware of the importance of ICT for the development of their activities, but some financial, human, geographical and training aspects slow down the process.
\end{abstract}

\section{Keywords}

Information and communications technology; Internet; Social media; Tourism companies; Quebec

JEL classification: Z32, Z29, R11 


\section{Introduction}

The technology boom of recent decades via the advent of the Internet and especially social media, has brought significant and profound changes in the global tourism industry. O’Connor (1999) and Buhalis (2003) identify three major technological waves and present an overall picture of their respective impacts on the industry. If the introduction of the computer reservation system and global distribution system (i.e. a reservation management platform for travel agencies, which allows these agencies to know the benefits, availability and prices) have helped support the activities of tourism enterprises in the 1970s and 1980s, the advent of the Internet age over the next decade and its widespread access during the 2000s has, according to the agencies, made them aware of the true transformational impact of the information and communications technology (ICT) industry. Meanwhile, tourist behaviour at different stages of planning and purchasing travel, as well as during and after the stay, has also dramatically changed due to this change to digital. Buhalis and O'Connor (2005) point out that the Internet and e-tourism, which allow interactivity and a constant interconnection between the various stakeholders, businesses and consumers, have initiated a wave or reorganization development processes, management and marketing of tourism products, thus revolutionizing the industry. Therefore, this rapid and constant evolution of different tools and uses of digital technology requires tourism professionals to adapt to these new market realities or to renew certain management styles and planning. However, few Quebec scientific studies have investigated this issue in terms of the suppliers of services and not just the clienteles. It is in this context that this study was conducted in the fall of 2013 with Quebec tourism businesses. The scientific approach presented in this article is based on a primary research question and two secondary issues:

Principal question: How does the Quebec tourism industry manage and adapt to technological advances in the field?

Secondary issues: How do Quebec tourism businesses use and manage their websites? How do Quebec tourism businesses use social media?

\section{Theoretical basis}

Several theoretical models have been proposed in recent years in order to explain the emergence, adoption and diffusion of information and communications technology (ICT) in the tourism industry. Among these, in particular, are the theory of diffusion of innovations introduced by Rogers $(1962,1965)$. Buhalis and Deimeiz (2004), as well and Migiro and Ocholla (2005), also stated in their studies on e-tourism and tourism businesses that the attributes of an innovation, that is, for example, its relative advantage, compatibility, simplicity, opportunity to test and its outreach, determined the speed of adoption within an organization. Rogers (1995) has also developed a sequence of steps in order to characterize the diffusion of innovation: the exposure (1), persuasion or the 
formation of a favourable attitude towards innovation (2), the decision to adopt (3), implementation (4) and the confirmation and strengthening of innovation based on the positive results of its use (5). Aldebert (2010) meanwhile resumed the theory developed by Reix (2004) to theorize changing uses of ICTs and their impact on tourism businesses. This model stipulates that if the exploitation of ICTs, while initially superficial, did not induce a low degree of processing, therefore, the potential benefits were limited. Along these same lines, Sigala, Christou, and Gretzel (2011), in their studies on social media and tourism, theorized and diagrammed the impact of Web 2.0 on the decision making of passengers as well as the tourism business operators. According to this model, Web 2.0 influences the way in which travellers search, find, produce and evaluate tourist information, thus in this same way, making them active consumers and producers and not only passive consumers. Conversely, the active involvement of travellers encourages tourism businesses to redefine their business model in order to meet the needs and expectations of this new generation of travellers. This brief theoretical path leads us to a subsequent, scientific literature review conducted to determine the degree of advancement of research dealing with ICT and tourism practices.

\section{Literature review}

Over the past 40 years, the rapid development of ICT has significantly disrupted the tourism industry. The importance of this technology wave, which is also reflected in the recent proliferation of the use of the ' $\mathrm{e}$ ' term and phrase (e-tourism, e-marketing, e-business, or e-commerce), is also reflected, according to Bulahis and Law (2008), in the literature, to the extent that few publications revolving around tourism and technology were published before the 1990s. On the other hand, the establishment of an annual conference dedicated to e-tourism (ENTER) in 1994, and the creation of the Journal of Information Technology \& Tourism in 1998, according to these authors, reflect the strong interest of a community of researchers with regard to these new challenges. Consequently, the research activities flourished and a multitude of publications could be observed (Bulahis \& Law, 2008). As such, Frew (2000) has even estimated the number of articles related to this field published between 1980 and 1999 at 665, while Leung and Law (2007), have identified over 4140 publications in six major journals related to the tourism and hotel industry between 1986 and 2005 (Annals of Tourism Research, Tourism Management, International Journal of Hospitality Management, Cornell Hotel and Restaurant Administration Quarterly and Journal of Hospitality E Tourism Research).

Many researchers have been interested in the theme of digital practices with relation to tourism since the 1990s (Buhalis, 1998; Connell \& Reynolds, 1999; Inkpen, 1998; O’Connor, 1999; Poon, 1993; Sheldon, 1997; Werthner \& Klein, 1999), with a particular emphasis, according to Gallouj and Leroux (2011) and Aldebert (2010), on the issue of the impact of ICT in the tourism sector. A large part of the research has actually made the examination of the challenges that service providers face in order to take full advantage of marketing and business opportunities offered by these new technologies. 
To this end, Buhalis (1998), Longhi (2004), and Stiakakis and Georgiadis (2011) first point out that if ICT offers companies the opportunity to strengthen their competitive positions by cutting costs, expanding their market and their distribution channel, these also generate the entrance of new external and virtual players that significantly affect the competitive environment. These may, in fact, undermine or compromise the position of the traditional players. Bédard (2000) goes in the same direction with particular emphasis on the case of travel agencies. He demonstrates that they seek to ensure their sustainability and maintain their relevance in the market through various strategies of specialization and adaptation such as networking groups. Stiakakis and Georgiadis (2011) suggest the development of an integrated digital e-business strategy type to limit the negative implications of the Internet and ICT in general. Thus, although some researchers have drawn attention to the increasing disintermediation of the industry in a growing e-commerce context (Buhalis, 1998; Buhalis \& Licata, 2002; Stamboulis \& Skayannis, 2003; Zelenka, 2009), others such as Suárez Álvarez et al. (2007), stray from the view that ICT constitutes a real threat to traditional travel agencies. They stipulate that the use of the Internet allows these companies to offer online services, in addition to their physical service, which is, from their point of view, a competitive advantage that helps to consolidate their position in the market. Thus, it seems clear that ICTs fundamentally blur the traditional structure of the tourist offer (Gallouj \& Leroux, 2011) and put enormous pressure on traditional intermediaries (Buhalis \& Licata, 2002; Zelenka, 2009). This technology does not suggest the complete substitution of traditional staff through electronic intermediaries. According to Samantha (2010), it often remains difficult for some less experienced individuals to surf the Internet. Rival (2008) raises the question of the development of a complementary tool.

Zelenka (2009) discusses current trends in ICT in the tourism sector, particularly emphasising the increasing importance of tourist communities on websites such as blogs. If the fact of publicizing its assessment of certain products, services or tourist destinations is good for consumers (Banyai \& Havitz, 2013; Gavalas et al., 2014), this trend is also considered as a marketing and promotional tool for an inexpensive, strategic tool for tourism and hospitality, according to Litvin et al. (2008). The impact of websites on consumer behaviour, especially with regard to the choice of tourist destinations (Frias et al., 2008; Steinbauer \& Werthner, 2007), and the effect of the electronic word-of-mouth on the process of consumer decision making (Litvin et al. 2008; Jalilvand et al., 2012), have been studied by some researchers. The tourism industry should draw on the results of these studies to exploit these tools more adequately. The effects of electronic wordof-mouth have also been exacerbated by the recent development of social media, which play a growing role in online tourism, according to Xiang and Gretzel (2010), Sigala, Christou and Gretzel (2011), Hays et al. (2012), Law et al. (2014), Kang and Schuett (2013), Nusair et al. (2013), Tham et al. (2013), and Law, Buhalis, and Cobanoglu (2014). Studies by Gavalas et al. (2014,) and Kim and Law (2015) also witness the rapid evolution of these platforms by drawing up a comprehensive picture of mobile recommendation services and the latest, interactive and growing popularity of smart phones in research and the sharing of visitor information. Mamaghani (2009) states that tourism marketing 
strategies should continually evolve with the advancement of information technology and user habits. Businesses must constantly adjust in order to thrive in a highly competitive and rapidly changing environment (Buhalis \& O'Connor, 2005), and only creative and innovative providers will be able to survive the competition (Buhalis, 1998; Longhi, 2004). According to Ali and Frew (2014), the perpetual innovation in the tourism industry also participates in the development of a more sustainable tourism.

If Buhalis (2003) and Stiakakis and Georgiadis (2011) argue that ICT has maximized the effectiveness and efficiency of the organization of tourism, Aldebert and Guegan (2013) point out that research on the link between ICT and performance does not reflect a direct, positive and systematic relationship. ICT alone is not enough to fully explain the strategic benefits obtained. Exploiting the full potential of ICTs to improve the company's performance necessarily implies, according to Werthner and Klein (1999), Aldebert (2008) and Gallouj and Leroux (2011), a change in working methods and a change in the tasks and their distribution in the tourism business. Along the same line, Rival (2008) emphasizes the existence of a particularly important link between the consistency of organizational choices and business performance. However, if the development of a strategic alignment between the managerial components, according to Rival (2008), enables the achievement of satisfactory results, it remains rather more delicate and difficult to implement in existing businesses due to their respective backgrounds in managerial practices. The development of strategies to increase competition and performance, in this context, has been described in many studies; however, little information with regard to the impacts that ICT has on the strategic management of small and medium enterprises (SME) is available. Moreover, although the technology is a cornerstone and catalyst for innovation, it must necessarily be accompanied and supported by important organizational changes in terms of circuits of production and distribution, as well as combined with other strategic measures such as capacity building and human resource management (Blake et al., 2006). Research revolving around innovation in the tourism industry is also in its infancy and continues to grow (Aldebert et al., 2011; Ali \& Frew, 2014; Buhalis \& Law, 2008; Caccomo \& Solonandrasana, 2001; Carvalho \& Sarkar, 2014; Hjalager, 2010; Stamboulis \& Skayannis, 2003).

While most studies have dealt mainly with European and North American countries, a number of them dealing with technologically less-developed countries seem to be gradually emerging over the dissemination and expansion of ICT in this sector, thus opening the door to new avenues of research. Zelenka (2009) foresees the eventual replacement of traditional commerce by e-business in developing countries. However, Buhalis and Deimezi (2004), Heung (2003), Migiro and Ocholla (2005), Abou-Shouk et al. (2013) and Anwar et al. (2014) have documented key barriers to the adoption of these technologies in Greece, Hong Kong, and South Africa, while Bédard and Kadri (2004) insist on the digital North/South division of tourism which is still strongly present. 


\section{Methodology}

From a methodological point of view, this study is based on a quantitative approach using the administration of a survey by questionnaires. Data collection took place between October 17 - 31, 2013. However, and due to a ban on the use of these results imposed by funders of this study, it has not been possible, until a few months ago, to publish these results in a scientific journal. This period was selected to conduct this investigation as it is the "off-season" for most players in the tourism sector. Their availability to answer the questionnaire was, therefore, greater. The survey was administered via the Internet and was sent to 9, 305 tourism companies in Quebec. Note that the major part of the sample comes from Tourisme Québec's database (more than 14,000 companies), composed of 93 types of tourism businesses. The final sample was established following a classification performed to remove non-relevant organizations for the purpose of this survey (non-tourist restaurants or businesses without a tourist vocation). Following two reminders sent by email, 2,393 people agreed to answer the questionnaire. Regarding the latter, it consisted of 44 closed questions (dichotomous, multiple-choice and rating scales) relating to 11 themes: facilities and the Internet access, management of client relationships, website optimization, mobility, online booking, web presence, social media, e-reputation, and assessment of your needs and your organization's profile. This data collection instrument was designed by the research team for this study in partnership with the study's sponsors. It is important to note that this instrument is inspired by several existing questionnaires and from scientific literature in the field. However, for the purposes of this article, we will present only the data related to the management of the Internet sites and the use of social media by tourism businesses. With regard to the analysis of the data, SPSS software and SAS software were used in order to make a first selection (frequencies and percentages) and later, to perform certain crosses based on various sociodemographic variables as well as certain statistical tests (Khi-deux, test of Student).

\section{Results}

\section{Profile of respondents of tourism businesses}

Among all tourism business respondents $(n=2,393), 46 \%$ are related to the accommodations field, $23 \%$ to the cultural sector, $18 \%$ in the field of leisure, $8 \%$ in the catering sector and $5 \%$ in the general supplier of tourist services. More specifically, we find that the majority of respondents are related to some specific business sectors: bed and breakfast, tourism accommodations, restaurants and cultural spaces.

From a geographical perspective, $16 \%$ of responding companies are from urban areas, $13 \%$ of these areas are near the two main cities of Quebec (Quebec and Montreal), while the rest are from more remote or very remote areas. In addition to the image and the known realities of the tourism industry in Quebec, the majority $(60 \%)$ of the companies that participated in the study are small (1-4 employees) and 16\% have between 5-10 employees. The other responding companies have more than 11 employees. It may 
be noted that the majority $(64 \%)$ of tourism business who responded are in operation throughout the year. However, the summer season is the time when companies that do not operate year-round are the most active (46\%). With regard to the operating budget, $35 \%$ of responding companies have a budget of between 0 and $\$ 50000$ annually. Only $15 \%$ of organizations surveyed have a higher annual budget of $\$ 500000$. However, $16 \%$ of the sample did not respond to this question.

\section{Presence and management of ICT}

Initially, several tourist companies say that they offer the Internet access to their customers in various forms. For $64 \%$ of respondents, the Internet is available as free $\mathrm{WiFi}$, while $3 \%$ offer it for a small fee. About $13 \%$ offer access to the Internet using a computer made available to customers. Only a minority use multimedia terminals $(1 \%)$ or digital tablets which are available to the customers $(1 \%)$. Complementarily, it was noted that almost all $(97 \%)$ of tourism business respondents use email to communicate with their customers. When participating companies were questioned regarding the fact that they had a website or not, $85 \%$ answered yes. As well, the cross-conducted analyses show a disparity in terms of size and geographical location of the company. As such, there is a significant difference $(\mathrm{p}<.001)$ between the geographic location, company size and the presence and use of a website. Parallelly, tourist organizations of fewer than five employees and those located in more remote areas or urban centres each have a website (78\% and $75 \%$ ), as compared to over $93 \%$ for companies with more than five employees and $90 \%$ for those located in urban areas. When cross analysing the data by sector of activity, there is a high proportion of tourist accommodations, cottages, condos or apartments, which have no website (33\%). Host villages (27\%) and alpine ski centres (22\%), are also among the sectors having a greater proportion of businesses without websites. Besides the lack of budget, reasons for not having a website include:

- $33 \%$ - that the activity does not justify having a website;

- $30 \%$ - lack of time;

- $28 \%$ - due to the absence of qualified human resources personnel;

- $22 \%$ - too complex;

- $18 \%$ - do not believe in the pertinence or need.

With regard to the management of their website, $34 \%$ of tourism business respondents indicate that they manage their website completely in-house, while $43 \%$ of respondents indicate that only part of the website is managed internally. Nearly $19 \%$ of participating organizations rely on an external third party to manage their website, while $4 \%$ do not have the resources to have someone manage it. For tourism businesses that perform management of their site internally, the majority (59\%) spent less than five (5) hours monthly managing their site, while 25\% will dedicate between 5 - 10 hours per month. For the large part, tourism businesses that were surveyed (93\%), stated that 
their website provides information about days of operation, activities offered, services, or rates. A large proportion is dedicated to photos or videos $(86 \%)$ which highlight the products or services offered. Many (61\%) also position their business on a Google map. However, few of the participating companies (14\%) link reviews of vacations to such sites as TripAdvisor. Only $2 \%$ of respondents have the chat feature.

Furthermore, nearly $60 \%$ of respondents say that tourism businesses measure hits on their websites. To do this, the following tools are used:

- $32 \%$ use statistics provided by the company who manages or houses their website;

- $32 \%$ use a Google Analytics account;

- $10 \%$ use a visitor counter on their website;

- $5 \%$ prioritize some other measurement tool.

Statistics collected through the use of these tools allows, among other things:

- $\quad$ to determine the traffic on the site $(82 \%)$;

- to show the evolution of traffic on the site $(80 \%)$;

- to show the number of visitors (66\%);

- the pages where the visitors spend most of the time $(48 \%)$.

With regard to the reputation of tourism enterprises, the majority of respondents (52\%), say that they do not perform any monitoring online. Meanwhile, some $23 \%$ monitor guest comments and only $11 \%$ say they monitor and respond to reviews. The cross-analyses also show that over $60 \%$ of enterprises in urban centres monitor their reputation, while more than $53 \%$ of those located in remote and very remote regions to urban centres do not. In this respect, it may be noted that the difference is significant at $p=0.007$ between the geographical location and monitoring of the reputation of the Internet business.

\section{Use of social media}

Among all responding organizations, Facebook and YouTube are the most popular social media. Meanwhile, the majority $(62 \%)$ of companies surveyed use social media for business purposes. However, it is in urban areas where this percentage proves to be the highest $(70 \%)$, as compared to $58 \%$ in remote or very remote areas. For respondents who do not use social media, the reasons for this choice are rather mixed. The largest proportion (38\%), mentioned the lack of time as their main reason. There is also the fact that the organization's activity does not justify a presence in these different media $(27 \%)$. About one quarter $(26 \%)$ does not believe in the relevance or usefulness or does not have the human resources to manage these networks.

The cross analysis by sector shows that youth hostels stand out in their use of Facebook, while travel/reservation centres or ticket agencies tend to use Twitter and Lin- 
kedIn. The larger hotels $(200+$ rooms $)$ and transportation services are present in four social media (Facebook, Twitter, YouTube and LinkedIn). The companies involved in transportation services use YouTube more than all the other sectors.

Finally, and for most tourism businesses, one of the main reasons for their presence on social media is to disseminate information about their products and services $(84 \%)$. Over one third (36\%) also use these media to present promotion offers. It is, however, important to mention that there is a significant difference $(p=0.000)$ between the size of the tourism business and the two types of reasons.

\section{Need for knowledge and training with regard to ICT}

To better understand the expectations and needs of tourism businesses, companies were asked what their level of interest is with regard to different aspects of ICT. Overall, the two elements that seemed to interest respondents were the following:

- referencing a website and content optimization (67\%);

- performance measurement of a website $(68 \%)$.

Complementarily, cross-analyses show that tourism businesses located in urban areas would especially like to improve the referencing of their website and content optimization $(71 \%)$ and performance measurement of web sites $(70 \%)$. They also show more interest than the other companies surveyed for the Google Adwards campaigns (53\% and $\mathrm{p}=0.03)$ and the numerical relationship with customers $(53 \%$ and $\mathrm{p}=0.046)$. The more remote and very remote regions focus their needs more on performance measurement $(72 \%)$, the diagnosis of their website $(68 \%)$ and self-management of a website $(67 \%)$.

Finally, we note that to meet the learning needs of tourism businesses surveyed, the majority (55\%) of respondents support the establishment of training workshops or working within their region.

\section{Discussion}

The results are used to answer the research questions raised in the introduction. Indeed, this study clearly demonstrates that the Quebec tourism businesses are generally aware of the importance of ICT for development and growth of their business. However, the management of their websites and use of social media significantly differ depending on the financial capacity of these organizations, their geographical locations as well as their size and their human resources. The data presented shows that the more a tourism business is small and is far from major urban centres, the more it has difficulty in adapting to the new realities of ICT in the tourism industry. This finding is even more glaring when one focuses on the integration of vacationers and the monitoring of its reputation as it truly seems to be a digital divide between organizations located in urban communities and those located in remote or very remote areas. These results correlate with those of 
Gallouj and Leroux (2011), Rival (2008) and Aldebert (2008) who see the development and consolidation of ICT in the world tourism industry as a major impact on the human and managerial structures of these organizations. Consequently, for authors such as Blake et al. (2006), ICT is undoubtedly a catalyst for development or innovation for these companies, but they must be accompanied, during their implementation, by training, which is sometimes quite difficult to set up in small companies.

With regard to social media, these are proven to be generally used, regardless of the companies' sector. As such, many of the respondents plan and perceive social media as privileged opportunities for loyalty, awareness and interaction with customers. These results correspond to studies by Law et al. (2014), Hays et al. (2012) and Xiang and Gretzel (2010), who now see social media as essential elements of the tourism industry. However, it appears surprising that many organizations do not yet seem to realize the importance of social media for the development of their activities.

It is to be noted, however, in a complementary way, that tourist companies using the least social media seem to be mostly new, smaller-size ones, since a lack of time and skilled labour are reasons given. This analytical finding once again suggests a real fracture in Quebec between small and major tourist organizations, despite the fact that the use of social media may appear initially accessible to all.

Finally, this study clearly shows a need for knowledge and training for the various respondents in the tourism business. This is consistent with Mamaghani (2009) and Buhalis and O'Connor's (2005) rationale who believe that tourism businesses must continually train and thus innovate through ICT as the economic environment has become extremely competitive. However, these requirements do not turn out identical or homogeneous for all. Note again a geographical disparity between urban tourism organizations who may use new ICT more often while those located in more remote areas, seem more concerned to better control the daily management of the communication and promotion strategies. Meanwhile, it denotes sectors (water park / zoo / theme site / garden, hostel and relaxation / spa) that are more anxious to learn how to optimize online content, who will systematically take into account their clients' comments and thereby seek to interact with them and develop innovative promotion strategies. This can be explained by the fact that these tourism businesses want to attract and welcome a younger clientele. This Quebec reality observed through this study, agrees with the comments and studies by Litvin et al. (2008), Frias et al. (2008) and Steinbauer and Werthner (2007). Thus, these results and more generally, this study, make it possible to note significant disparities in this industry with relation to geographic features or human resources. These findings are not surprising since, for several years now, different actors in the Quebec tourism industry speak of a fragmentation or excessive heterogeneity of the tourism sector, as well as other parts of society (e.g. education, transportation, or health). In this context, this study confirms these claims and expose various actions which could be taken over the short and medium terms. 


\section{Conclusion}

This study identifies the importance of ICT in Quebec tourist companies. Many have taken part in the digital movement; however, other progressive possibilities persist. At the same time, important differences are observed between sectors, large and smaller companies as well as between those situated in urban areas and those located in remote or very remote areas. However, despite these sometimes difficult organizational realities, it is possible to note a strong accompanying desire to improve certain shortcomings in terms of digital presence and use of ICT. This training would eventually allow more tourism businesses to monitor their online reputation, interact with current and prospective customers and to develop innovative communication and promotional strategies, especially via social media. Overall, this study, on an unprecedented scale in Quebec, undeniably brings to light different trends in knowledge and use of ICT, while highlighting some critical needs or various development avenues to prioritize. Therefore, the results presented can be seen both as a scientific diagnosis to achieve a state of the target location on a central issue of the Quebec tourism industry, as well as elements contributing or aiding in the development of public and private strategic interventions in this sector.

In conclusion, it is important to note the limitations of this study. First of all, and due to certain ethical considerations and confidentiality imposed by sponsors of this study, the data presented was collected in the fall of 2013. Therefore, it is, of course, possible that a new study conducted today on this issue could lead to different results. However, several recent studies conducted by the "Réseau de veille en tourisme" and Tourism Montréal as well as during the annual tourism conference in Quebec, show that there is still a significant need for knowledge and training in ICT. Although such research is often conducted via smaller samples that those presented in this article, the fact remains that the results illustrate that this issue related to ICT is central in this industry in Quebec due to the important geographical and human disparities existing in this Canadian province. Moreover, the self-administered questionnaire cannot allow us to guarantee the identity of respondents and their level of understanding of each question and each of the submitted responses. Finally, this study is based on a purely quantitative approach and does not actually increase our knowledge of some core elements. The use of complementary, qualitative data collection techniques (semi-structured interviews or focus groups), would no doubt have brought an additional analytical aspect.

\section{Acknowledgements}

The authors would like to thank the anonymous reviewers of this article for their insightful comments. We would also like to thank the Transat Chair in Tourism at the University of Quebec in Montreal (UQAM) for allowing us access to different empirical data as well as all the partners of this study: Tourisme Québec, ATR Associates of Quebec and ATS Québec. 


\section{References}

Abou-Shouk, M., Megicks, P., \& Lim, W. M. (2013). Perceived benefits and e-commerce adoption by SME travel agents in developing countries: Evidence from Egypt. Journal of Hospitality and Tourism Research, 37(4), 490-515. DOI: 10.1177/1096348012442544

Aldebert, B. (2008). Technologies de l'information et de la communication : un outil stratégique pour les petites et moyennes entreprises touristiques?. Management et Sciences Sociales, 5(September), 1-21.

Aldebert, B. (2010). Technologies de l'information et de la communication et innovation. Application à l'industrie touristique. Thèse de doctorat (Doctoral Thesis). France: Éditions Universitaires Européenne.

Aldebert, B., \& Gueguen, G. (2013). TIC et performance : rôle du dirigeant de PME touristiques. Revue internationale P.M.E. : économie et gestion de la petite et moyenne entreprise, 26(3-4), 213-233.

Aldebert, B., Dang, R. J., \& Longhi, C. (2011). Innovation in the tourism industry: The case of Tourism@, Tourism Management, 32(5), 1204-1213. DOI: 10.1016/j.tourman.2010.08.010

Ali, A., \& Frew, A. J. (2014). ICT and sustainable tourism development: An innovative perspective. Journal of Hospitality and Tourism Technology, 5(1), 2-16.

Anwar, M. A., et al. (2014). The diffusion and impacts of information and communication technology on tourism in the Western Cape, South Africa. Urban Forum, 25, 531-545. DOI: 10.1007/ s12132-013-9210-4

Banyai, M., \& Havitz, M. E. (2013). Analyzing travel blogs using a realist evaluation approach.Journal of Hospitality Marketing and Management, 22(2), 229-241. DOI: 10.1080/19368623.2012.680239

Bédard, F. (2000). Stratégies d'adaptation aux nouvelles technologies dans les services. Essai de modélisation du comportement des agences de voyage. Thèse de doctorat. Paris: Université Paris 1 PanthéonSorbonne.

Bédard, F., \& Kadri, B. (2004). Les technologies de l'information comme facteur d'autonomie des destinations touristiques du Sud. Téoros, 23(2), 68-72.

Blake, A., Sinclair, M.T., \& Soria, J.A.C. (2006). Tourism productivity: evidence from the UK. Annals of Tourism Research, 33(4), 1099-1120. DOI: doi:10.1016/j.annals.2006.06.001

Buhalis, D. (1998). Strategic use of information technologies in the tourism industry. Tourism Management, 19(5), 409-421. DOI: 10.1016/S0261-5177(98)00038-7

Buhalis, D. (2003). eTourism: Information technology for strategic tourism management. London: Prentice Hall.

Buhalis, D., \& Deimezi, O. (2004). E-tourism developments in Greece: Information communication technologies adoption for the strategic management of the Greek tourism industry. Tourism and Hospitality Research, 5(2), 103-130. DOI: 10.1057/palgrave.thr.6040011

Buhalis, D., \& Law, R. (2008). Progress in information technology and tourism management: 20 years on and 10 years after the Internet. The state of eTourism research. Tourism Management, 29(4), 609-623. DOI: 10.1016/j.tourman.2008.01.005

Buhalis, D., \& Licata, M.C. (2002). The future eTourism intermediaries. Tourism Management, 23(3), 207-220. DOI: 10.1016/S0261-5177(01)00085-1

Buhalis, D., \& O'Connor, P. (2005). Information communication technology revolutionizing tourism. Tourism Recreation Research, 30(3), 7-16. DOI: 10.1080/02508281.2005.11081482 
Caccomo, J. L., \& Solonandrasana, B. (2001). L'innovation dans l'industrie touristique : enjeux et stratégies. Paris : L'Harmattan.

Carvalho, L.M.C., \& Sarkar, S. (2014). Market structures, strategy and innovation in tourism sector, International Journal of Culture. Tourism and Hospitality Research, 8(2), 153-172.

Connell, J., \& Reynolds, P. (1999). The implications of technological developments on Tourist Information Centers. Tourism Management, 20(4), 501-509. DOI: 10.1016/S0261-5177(99)00007-2

Frew, A. J. (2000). A critical analysis of tourism information technology research. In D. Fesenmaier (Ed.), Information and communications technologies in tourism (pp. 39-52). Vienne, Austria: Springer.

Frias, D. M., Rodriguez, M. A., \& Castaneda, J. A. (2008). Internet vs. travel agencies on pre-visit destination image foundation: An information processing view. Tourism Management, 29(1), 163179. DOI: $10.1016 /$ j.tourman.2007.02.020

Gallouj, C., \& Leroux, E. (2011). E-tourisme, innovation et modes d'organisation. Management $\mathcal{E}^{\circ}$ Avenir, 22(4), 213-231. DOI: 10.3917/mav.042.0213

Gavalas, D., et al. (2014). Mobile recommender systems in tourism. Journal of Network and Computer Applications, 39(March), 319-333. DOI: 10.1016/j.jnca.2013.04.006

Hays, S., Page, S., \& Buhalis, D. (2012). Social media as a destination marketing tool: Its use by national tourism organizations. Current Issues in Tourism, 16(3), 211-239. DOI: $10.1080 / 13683500.2012 .662215$

Heung, V. C. S. (2003). Barriers to implementing e-commerce in the travel industry: A practical perspective. International Journal of Hospitality Management, 22(1), 111-118. DOI: 10.1016/S02784319(02)00075-0

Hjalager, A. M. (2010). A review of innovation research in tourism. Tourism Management, 31(1), 1-12. DOI: 10.1016/j.tourman.2009.08.012

Inkpen, G. (1998). Information technology for travel and tourism. Essex, UK: Addison Wesley Longman.

Jalilvand, M. R., et al. (2012). Examining the structural relationships of electronic word of mouth, destination image, tourist attitude toward destination and travel intention: An integrated approach. Journal of Destination Marketing and Management, 1(1), 134-143. DOI: 10.1016/j. jdmm.2012.10.001

Kang, M., \& Schuett, M. A. (2013). Determinants of sharing travel experiences in social media. Journal of Travel and Tourism Marketing, 30(1), 93-107. DOI: 10.1080/10548408.2013.751237

Kim, H. H., \& Law, R. (2015). Smartphones in tourism and hospitality marketing: A literature review. Journal of Travel E Tourism Marketing, 32(6), 692-711. DOI: 10.1080/10548408.2014.943458

Law, R., Buhalis, D., \& Cobanoglu, C. (2014). Progress on information and communication technologies in hospitality and tourism. International Journal of Contemporary Hospitality Management, 26(5), 727-750. DOI: 10.1108/IJCHM-08-2013-0367

Leung, R., \& Law, R. (2007). Analyzing research collaborations of information technology publications in leading hospitality and tourism journals: 1986-2005. In M. Sigala, L. Mich, \& J. Murphy (Eds.), Information and communication technologies in tourism (pp. 547-557). Vienne, Austria: Springer.

Litvin, S. W., Goldsmith, R. E., \& Pan, B. (2008). Electronic word-of-mouth in hospitality and tourism management. Tourism Management, 29(3), 458-468. DOI: 10.1016/j.tourman.2007.05.011 
Longhi, C. (2004). Internet et dynamique des marchés dans le tourisme - Enjeux analytiques et développements empiriques. Revue d'économie industrielle, 108(1), 67-90. DOI: 10.3406/rei.2004.3059

Mamaghani, F. (2009). Impact of e-commerce on travel and tourism: An historical analysis. International Journal of Management, 26(3), 365-375.

Migiro, S. O., \& Ocholla, D. N. (2005). Information and communication technologies in small and medium scale tourism enterprises in Durban, South Africa. Information Development, 21(4), 283294. DOI: $10.1177 / 0266666905060089$

Nusair, K., et al. (2013). Generation Y travelers' commitment to online social network websites. Tourism Management, 35(1), 13-22. DOI: 10.1016/j.tourman.2012.05.005

O'Connor, P. (1999). Electronic information distribution in tourism and hospitality. Wallingford Oxon: Cabo Publishing.

Poon, A. (1993). Tourism, technology and Competitive Strategies. Oxon: C.A.B. International, Free Press.

Reix, R. (2004). Systèmes d'information et management des organisation. Vuibert: Entreprendre.

Rival, Y. (2008). Internet et performance de l'entreprise. Une analyse des stratégies Internet appliqué au secteur du tourisme. Thèse de doctorat publiée. Paris: L'Harmattan.

Rogers, E. M. (1995). Diffusion of innovations. New York: The Free Press (4e édition) [1962].

Samantha, I. (2010). Internet in marketing strategy in Greek tourism industry. In M. Lytras et al. (Ed.), Digital culture and e-tourism. Technologies, applications and management approaches. New York: IGI Global.

Sheldon, P. J. (1997). Tourism information technology. Oxford: Cabi Publishing.

Sigala, M., Christou, E., \& Gretzel, U. (2011). Social media in travel, tourism and hospitality. Theory, Practice and Cases. UK: Ashgate.

Stamboulis, Y., \& Skayannis, P. (2003). Innovation strategies and technology for experience-based tourism. Tourism Management, 24(1), 35-43. DOI: 10.1016/S0261-5177(02)00047-X

Steinbauer, A., \& Werthner, H. (2007). Consumer behavior in e-Tourism. In M. Sigala, L. Mich \& J. Murphy (Eds.), Information and Communication Technologies in Tourism 2007 (pp. 65-76). Vienna: Springer Vienna.

Stiakakis, E., \& Georgiadis, C. K. (2011). Drivers of a tourism e-business strategy: The impact of information and communication technologies. Operational Research, 11(2), 149-169. DOI: 10.1007/ s12351-009-0046-6

Suárez Álvarez, L., Diaz Martín, A. M., \& Vázquez Casielles, R. (2007). Relationship marketing and information and communication technologies. Analysis of retail travel agencies. Journal of Travel Research, 45(4), 453-463. DOI: 10.1177/0047287507299593

Tham, A., Croy, G., \& Mair, J. (2013). Social media in destination choice: Distinctive electronic word-of-mouth dimensions. Journal of Travel and Tourism Marketing, 30(1), 144-155. DOI: $10.1080 / 10548408.2013 .751272$

Werthner, H., \& Klein, S. (1999). Information technology and tourism: A challenging relation. Vienna: Springer Verlag.

Xiang, Z., \& Gretzel, U. (2010). Role of social media in online travel information search. Tourism Management, 31(2), 179-188. DOI: 10.1016/j.tourman.2009.02.016

Zelenka, J. (2009). Information and communication technologies in tourism. Influence, dynamics, trends. EESM Economics and Management, 9(1), 123-132. 